Article

\title{
Design, Manufacturing, and Flight Testing of an Experimental Flying Wing UAV
}

\author{
Pei-Hsiang Chung ${ }^{1}$, Der-Ming Ma ${ }^{2} \mathbb{D}$ and Jaw-Kuen Shiau ${ }^{2, *}$ \\ 1 Department of Mechanical and Electro-Mechanical Engineering, Tamkang University, \\ New Taipei City 25137, Taiwan \\ 2 Department of Aerospace Engineering, Tamkang University, New Taipei City 25137, Taiwan \\ * Correspondence: shiauj@mail.tku.edu.tw; Tel.: +886-2-2621-5656 (ext. 3318)
}

Received: 30 April 2019; Accepted: 25 July 2019; Published: 28 July 2019

\begin{abstract}
This paper presents the design, manufacturing, and flight testing of an electric-powered experimental flying wing unmanned aerial vehicle (UAV). The design process starts with defining the performance requirements including the stall speed, maximal speed, cruise altitude, absolute ceiling, and turn radius and speed. The wing loading and associated power loading are obtained based on the defined performance requirements. The wing area, UAV mass, and power requirements are determined from the endurance and payload requirements. The power requirement determines the motor size. Aerodynamics and stability designs are obtained based on the selected airfoil and obtained wing area. After completing the design, the UAV is manufactured using composite materials. The UAV is equipped with an AXi 4130/20 kv305 brushless motor and a Pixhawk flight control board. Its total weight is $8.6 \mathrm{~kg}$. Flight tests were conducted to evaluate the UAV's performance and dynamic characteristics and to demonstrate the success of the design.
\end{abstract}

Keywords: unmanned aerial vehicle (UAV) design; flight testing; flying wing

\section{Introduction}

The development of unmanned aerial vehicles (UAVs) has attracted much attention in the aviation industry for decades, especially in the United States. Goraj [1] noted that the current UAV market is predominantly driven by military requirements. The mainly military applications of UAVs include reconnaissance, transport, and search and rescue. This study noted that operational costs, safety, and multirole capabilities are the dominant factors driving civilian UAV applications. A report from the US Department of Defense (DoD) addressed some significant technologies needed for various UAVs [2]. These technologies can be supported by the current state-of-the-art technology. As the US DoD develops the more multi-functional UAVs, other countries are following the same strategic rules and are developing or purchasing such systems. The current state-of-the-art technology provides low-cost and high-performance sensors, communication, navigation, guidance, and control. For example, Pixhawk 4 (or Ardupilot) is a common and low-cost flight control and navigation system hardware for civilian, research, or hobbyist use. It consists of an inertial measurement unit (IMU) (gyroscopes and accelerometers), magnetometer (compass), barometer, global positioning system (GPS) module, power system, and interfaces. Its powerful autopilot software can handle all flight control and navigation requirements of the UAV. Low-cost UAVs have a significant influence on the overall value and specific applications in the aviation industry.

Aerodynamic design plays a crucial role in an aircraft's conceptual design. An aerodynamic design layout strongly influences the aircraft's structures and systems, and in turn, its manufacturing process. Good aerodynamic design enables an aircraft to have good performance and reduces costs via lower fuel consumption. At the start of the aircraft's conceptual design, many parameters must 
be determined. Studies have developed aircraft conceptual design methodologies for conventional aircrafts [3,4] and analyzed various techniques for this purpose [5]. Loftin developed the matching of sizing aircraft performance methods for subsonic aircrafts [6]. Hydrocarbon fuels such as petroleum are used most commonly in aircrafts. Therefore, the development of conventional design methodologies is based on hydrocarbon fuels [3-5].

Flight duration depends on the energy carried by the UAV. The energy density of petroleum, lithium-ion batteries, and lead-acid batteries are 46.4, 0.36-0.88, and $0.17 \mathrm{MJ} / \mathrm{kg}$, respectively. High-energy-density fuels enable lower weights and better performance under the same flight conditions. Therefore, the use of low-energy-density fuels in aircraft design is a research challenge. Further, the weight strongly influences the aircraft's power consumption, making it challenging to design a battery that can satisfy the aircraft's required range and endurance. Gokcin developed a methodology for sizing the electric propulsion subsystems of UAVs [7]. An electric-powered UAV is heavier than a petroleum UAV in all scenarios. If the energy density of batteries is increased in the future, electric-powered UAVs with reduced battery weight and improved performance can be realized.

With improvements in avionics devices such as the battery and electric motors, electric-powered UAVs have attracted increasing research attention. Recently, Traub derived equations for evaluating the range and endurance of electrical aircrafts [8]. This study considered the effects of Peukert's law on the battery discharge process to provide a better concept for battery weight design. Later, Giulio presented a simple example for determining the correct values of the best range conditions [9]. Flight test methods were developed for a small, electric-powered flying wing UAV [10]. This study successfully found the drag polar and various performance parameters including the range, endurance, climb performance, and turn performance for electric-powered flying wing UAVs.

Sunlight is considered inexhaustible, and solar-powered UAVs can be in continuous flight in theory if they do not require maintenance. Therefore, many researchers have focused on solar-powered aircrafts. Brandt presented a methodology for the conceptual design of a solar-powered aircraft [11]. They combined a Roskam-style parameter formulation with Morgan's solar power notation. This provides a design methodology that is useful and easy to understand. Recently, genetic algorithms were used for optimizing aerodynamic configuration designs. Many studies have focused on optimizing aerodynamic configurations and the efficiency of evolutionary computational algorithms.

The tendency to get trapped in local minima is a shortcoming in conventional gradient-based optimization techniques. Genetic algorithms are more efficient than conventional gradient-based optimization techniques. An optimal sizing method based on genetic algorithms, minimum power cruising speed, and mass parameterization was developed [12]. Another study presented an aerodynamic performance design of a solar-powered aircraft and its solar power management system design [13]. This design and system were verified through successful ground and flight tests, making this Taiwan's first solar-powered UAV.

Lyu [14] noted that fuel burn reduction is an important issue in aircraft design research, especially in civil aviation. To use an unconventional aircraft configuration, such as the flying wing, is a possible way to reduce fuel burn, but the design of flying wing is accompanied by new challenges. The strong coupling between aerodynamic performance and stability is not easy to handle in the flying wing design. They believe that numerical optimization is useful to find the best possible flying wing configuration. Later, Charles presented a multidisciplinary design optimization study of an electric flying wing [15]. A powered wind tunnel testing of the hybrid wing body (HWB) was completed by Lockheed Martin (LM) and the Air Force Research Laboratory (AFRL) [16]. A subscale aircraft model was built and the test data was compared with computational fluid dynamic (CFD) simulations. The basic aerodynamic performance was validated in this study.

Considering the characteristics and constraints of electric-powered aircrafts, this study proposes a new integration method for electric-powered aircraft conceptual design. We report on the design, manufacturing, and flight testing of an electrically powered experimental flying wing UAV. The matching plot is a method for preliminary aircraft design that converts aircraft performance 
requirements into a wing loading $(\mathrm{W} / \mathrm{S})$ and thrust-to-weight ratio $(\mathrm{T} / \mathrm{W})$ or power loading $(\mathrm{W} / \mathrm{P})$ function and then finds the appropriate wing loading and thrust-to-weight ratio or power loading. Appropriate values are obtained from the intersection of the wing loading and thrust-to-weight ratio or power loading that can satisfy all performance requirements in the matching plot.

In the second section, the performance requirements of the electric-powered UAV are defined as the stall speed, maximum flight speed at cruising altitude, absolute ceiling, and turning radius and speed. Then, a matching plot is used to find the appropriate wing loading and power loading. In the third section, we propose estimating the UAV weight using the flight time and payload. The UAV's wing area and power requirements can be calculated from its weight and appropriate wing loading and power loading. Therefore, the UAV's motor specification can be well defined with the power budget. In the fourth section, airfoil selection, aerodynamic design, and stability design are considered, and these parameters are associated with the UAV's wing area.

In the fifth section, the manufacturing procedures for the electric-powered experimental flying wing UAV are reported. After design, composite materials are used to build the flying wing UAV. In consideration of its transportation and manufacturing, the aircraft is divided into three main parts - the fuselage section with left and right wing roots, left main wing section, and right main wing section-and two minor parts, the left and right wingtips. All parts are made of carbon fiber reinforced polymer, and the empty structure weight of the UAV is $6 \mathrm{~kg}$. We use an AXi 4130/20 kv305 electric brushless motor and the Pixhawk flight control system. The total weight of the UAV is $8.62 \mathrm{~kg}$.

The sixth section describes two flight tests. The first flight test is conducted to observe the basic flight with a remote controller. In the second flight test, we add the Pixhawk flight control system and its built-in gyroscope and accelerometer to record the flight parameters. In the seventh section, we discuss the effect of the UAV's increased weight on its performance requirements.

\section{Aircraft Conceptual Design}

As mentioned above, the energy density of an electric- or solar-powered aircraft is much lower than that of a traditional aircraft that uses petrol. Therefore, the aerodynamic configuration design of an electric aircraft is difficult compared with that of a traditional aircraft. Most aerodynamics design parameters are interrelated in the aircraft conceptual design process. It is not easy to find the best methodology for each type of aircraft. In practice, most designers often essentially complete a baseline configuration in the first design process. Then, they need to complete several iterations of the baseline configuration. The number of iterations depends on the designers' experience and the design database. Traditionally, iterations are used to obtain an acceptable solution for the overall design. A good designer can usually intuitively decide what should be changed to complete the design or to reduce the number of iterations.

Considering the battery's energy density and weight of structural materials, the critical challenge in reducing production costs and achieving design goals is to optimize the efficient use of battery energy. With the interaction between lift and drag forces, there is a specific cruise speed that minimizes the power required for a particular cruise altitude. Based on polar drag, the power required for a particular cruise altitude can be expressed in terms of the zero-lift drag coefficient and induced drag factor, assuming that the power required can be reduced through optimal design. Thus, the battery capacity and weight can be reduced, thereby reducing the aircraft weight. The lift required for cruising can be adjusted downward. In other words, the optimal design can effectively reduce the aircraft cost.

For aircraft design, most design parameters are interrelated. Re-evaluation of aircraft performance and recomputation of all other parameters are required to adjust a particular design parameter. The aircraft's zero-lift drag coefficient and induced drag factor are selected as parameters for the design procedure. The details of the design procedure are discussed below. Figure 1 shows the design procedure for the experimental flying wing UAV. At the start of the design process, empirical values for the aircraft's zero-lift drag coefficient and induced drag factor from the first calculation can be used temporarily. The matching plot is used to find the appropriate wing loading and power loading that 
can satisfy all given requirements. In the weight estimation approach, the maximum take-off weight is formulated and is estimated systematically. Then, the energy consumption and wing reference area of the aircraft are obtained. Aircraft aerodynamics and stability design starts with the given wing reference area. Then, the shape and configuration of the aircraft are determined. Software such as XFLR5[17] and DATCOM[18] can be used to estimate the zero-lift drag coefficient and induced drag factor of the aircraft. When these parameters are obtained, we can check their variations to ensure that the empirical value of the first calculation is appropriate. If the variations are smaller than desired, the design is considered complete. If the variations are larger than desired, the new zero-lift drag coefficient and induced drag factor of the aircraft are substituted into the next design process.

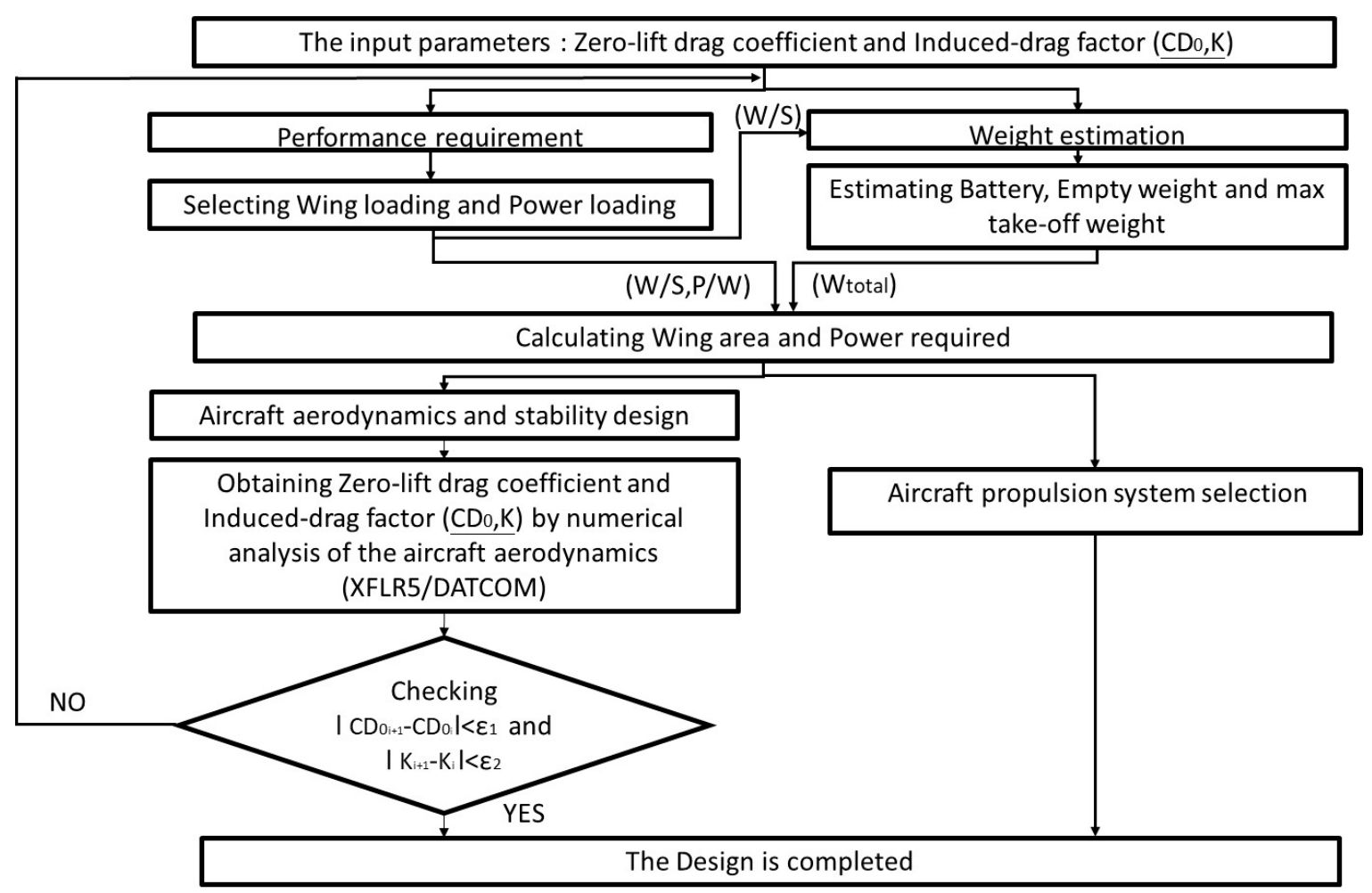

Figure 1. Design procedure for experimental flying wing unmanned aerial vehicle (UAV).

The matching plot is used to find the appropriate wing loading and power loading that can satisfy all performance requirements in the conceptual design process. The following subsections show the derivation of the performance requirements between wing loading and power loading [3-5]. A typical design process starts with the mission requirements for a new aircraft. The first process is conceptual design. In this section, the performance requirements of the electric-powered UAV include the stall speed, maximum speed at cruising altitude, absolute ceiling, and turning radius and speed.

\subsection{Stall Speed}

The stall speed is a limit to the minimum speed at which an aircraft can safely lift off from the ground. In the lift equation, the left- and right-hand-sides are the weight and lift, respectively. Because of the balance of forces, the wing area can be moved to the left side. Given the stall speed $\left(V_{s}\right)$ and the maximum lift coefficient $\left(C_{L_{\max }}\right)$, the wing loading is calculated as:

$$
\left(\frac{W}{S}\right)_{V_{s}}=\frac{1}{2} \rho V_{s}^{2} C_{L_{\max }}
$$

where $(W / S)_{V_{S}}$ is the wing loading required at the stall speed, the parameter $\rho$ is the air density at the sea level. 


\subsection{Maximum Speed at Cruising Altitude}

At cruising altitude $(100 \mathrm{~m})$, the cruising speed is 1.15 times the maximum lift-to-drag ratio speed and the maximum speed is 1.2 times the cruising speed. The speed for the maximum lift-to-drag ratio $\left(E^{*}\right)$ is based on the drag polar model and is calculated as:

$$
V_{E^{*}}=\sqrt{\frac{2}{\rho_{\infty}}\left(\frac{W}{S}\right) \sqrt{K / C_{D_{0}}}}
$$

where $K$ is the induced drag factor and $C_{D_{0}}$ is the zero-lift drag coefficient.

When a propeller-driven aircraft flies with the maximum constant speed at a specified altitude, the product of the maximum engine output power $\left(P_{\max }\right)$ and the efficiency of the propeller must be equal to the power required $\left(P_{\text {req }}\right)$ under the maximum constant speed condition. Because the engine output power decreases with increasing flight altitude, the relationship between engine power and altitude is considered based on the air density. According to the maximum speed $\left(V_{\max }\right)$ required at cruising altitude, the power loading at sea level can be calculated as:

$$
\begin{gathered}
\eta_{\operatorname{Pr}} P_{\max }=D V_{\max } \\
\frac{P_{\text {sealevel }} W_{\text {Total }} \sigma=}{=} \eta_{p} \rho_{\infty} \frac{S}{W_{\text {Total }}} C_{D_{0}} V_{\max }^{3}+K\left(\frac{2 W_{\text {Total }}^{2}}{\rho_{\infty} V_{\max } S W_{\text {Total }}}\right) \\
=\frac{1}{2} \rho_{\infty} C_{D_{0}} V_{\max }^{3} \frac{1}{\frac{W_{\text {Total }}}{S}}+\left(\frac{2 K}{\rho_{\infty} V_{\max }}\right)\left(\frac{W_{\text {Total }}}{S}\right) \\
\left(\frac{W}{P_{S L}}\right)_{V_{\max }}=\frac{\eta_{p r}}{\frac{1}{2} \rho_{0} C_{D_{0}} V_{\max }^{3} \frac{1}{\left(\frac{W}{S}\right)}+\left(\frac{2 K}{\rho \sigma V_{\max }}\right)\left(\frac{W}{S}\right)}
\end{gathered}
$$

In the equation, $D$ is the drag which includes the zero-lift drag and induced drag, and $\eta_{p r}$ is the propeller efficiency and $\sigma$ is the ratio of the cruising altitude density to the sea level density.

\subsection{Absolute Ceiling}

Ceilings are of four types: absolute, service, cruise, and combat. In this study, we consider the absolute ceiling. The absolute ceiling is the absolute maximum altitude at which an aircraft can safely perform straight level flight. In other words, the absolute ceiling is the altitude at which the rate of climb is zero. The rate of climb can generally be defined as the ratio of excess power to aircraft weight. Excess power is defined as the difference between the available and the required power. The maximum excess power and power loading at the absolute maximum altitude can be calculated as

$$
\begin{gathered}
R / C=\frac{P_{A}-P_{\text {req }}}{W_{\text {Total }}}=\frac{\eta_{\mathrm{Pr}} P-D V}{W_{\text {Total }}} \\
V_{(R / C)_{\max }}=V_{\left(P_{R}\right)_{\min }}=\sqrt{\frac{2 W_{\text {Total }}}{\rho_{\infty} S_{\text {ref }} \sqrt{\frac{3 C_{D_{0}}}{K}}}} \\
(R / C)_{\max }=\frac{\eta_{\operatorname{Pr}} P}{W_{\text {Total }}}-\frac{\frac{1}{2} \rho_{\infty} V_{(R / C)_{\max }}^{2} S_{w} C_{D}}{W_{\text {Total }}} \sqrt{\frac{2 W_{\text {Total }}}{\rho_{C} S_{\text {ref }} \sqrt{\frac{3 C_{D_{0}}}{K}}}} \\
\frac{W_{\text {Total }}}{P_{C}}=\frac{1}{\frac{(R / C)_{\max }}{\eta_{p r}}+\sqrt{\frac{2\left(W_{\text {Total }} / S\right)}{\rho_{C}} \sqrt{\frac{K}{3 C_{D_{0}}}}}\left[\frac{\left(\frac{1}{\sqrt{3}}+\sqrt{3}\right)}{2 E^{*} \eta_{p r}}\right]}
\end{gathered}
$$




$$
\left(\frac{W}{P_{S L}}\right)_{\text {ceiling }}=\frac{\sigma_{A C}}{\sqrt{\frac{2(W / S)}{\rho_{A C}} \sqrt{\frac{K}{3 C_{D_{0}}}}}\left[\frac{\left(\frac{1}{\sqrt{3}}+\sqrt{3}\right)}{2 E^{*} \eta_{p r}}\right]}
$$

where $\eta_{p r}$ is the propeller efficiency and $\sigma_{A C}$ is the ratio of the ceiling density to the sea level density.

\subsection{Turn Radius}

The minimum turn radius and the maximum turning rate are critical performance characteristics for a fighter aircraft. For the design of a commercial transport aircraft or experimental UAV, very high turning performance is not required. The required turning radius is $15 \mathrm{~m}$ at a speed of $10 \mathrm{~m} / \mathrm{s}$ and cruising altitude of $100 \mathrm{~m}$. The minimum turning radius is formulated. According to the required turn radius at a specific speed and cruising altitude, the power loading at sea level can be calculated as the following.

With the velocity, $V$, and load factor, $n$, at minimum turn radius [5]

$$
\left(V_{\infty}\right)_{R_{\min }}=\sqrt{\frac{4 K(W / S)}{\rho_{\infty}(T / W)}}, n_{R_{\min }}=\sqrt{2-\frac{4 K C_{D_{0}}}{(T / W)^{2}}}
$$

The minimum turn radius can be written as [5]

$$
\begin{aligned}
R_{\min } & =\frac{\left(V_{\infty}\right)_{R_{\min }}^{2}}{g \sqrt{n_{R_{\min }}^{2}-1}}=\frac{4 K(W / S)}{\rho_{\infty}(T / W)} \frac{1}{g \sqrt{2-\frac{4 K C_{D_{0}}}{(T / W)^{2}}}-1} \\
& =\frac{4 K(W / S)}{g \rho_{\infty}(T / W)} \frac{1}{\sqrt{1-4 K C_{D_{0}} /(T / W)^{2}}}
\end{aligned}
$$

The thrust can be replaced by the power

$$
T_{S L}=\frac{\eta_{p r} P_{S L}}{V_{R_{\min }}}
$$

Therefore, Equation (6) becomes

$$
R_{\min }=\frac{4 K(W / S)}{g \rho_{\infty}\left(\frac{\eta_{p r} P_{S L}}{V_{R \min }} / \mathrm{W}\right)} \frac{1}{\sqrt{1-4 K C_{D 0} /\left(\frac{\eta_{p r} P_{S L}}{W V_{\text {Rmin }}}\right)^{2}}}
$$

The power loading at the sea level is then

$$
\left(\frac{W}{P_{S L}}\right)_{\text {turn }}=\frac{\left(\eta_{p r} \sigma\right) / V_{\text {turn }}}{\left\{\left(\frac{V_{\text {turn }}^{4}}{(R g)^{2}}+1\right) \frac{K(W / S)}{0.5 \rho V_{\text {turn }}^{2}}+0.5 \rho V_{\text {turn }}^{2} \frac{C_{D_{0}}}{W / S}\right\}}
$$

where $\eta_{p r}$ is the propeller efficiency, $\sigma$ is the ratio of the cruising altitude density to the sea level density, $V_{\text {turn }}$ is the specific speed at the turning radius, and $R$ is the turning radius.

\subsection{Matching Plot}

The aerodynamics, propulsion, and flight performance must be determined during the conceptual design process. The preliminary sizing of the aircraft is performed using the matching plot proposed by Loftin. In a matching plot, the design problem is solved graphically; in this case, the two design variables are wing loading and power loading. Figure 2 shows a matching plot that satisfies the above performance requirements. The performance requirements are the stall speed, maximum speed, absolute ceiling, and turn radius, as shown in Figure 2. The maximum power loading (minimum 
power demand) at the intersection (area under blue solid line (2) and vertical black dashed line (1)) that satisfies all performance requirements simultaneously is $0.5899 \mathrm{Nt} / \mathrm{W}$, and the associated wing loading is $59.3 \mathrm{Nt} / \mathrm{m}^{2}$.

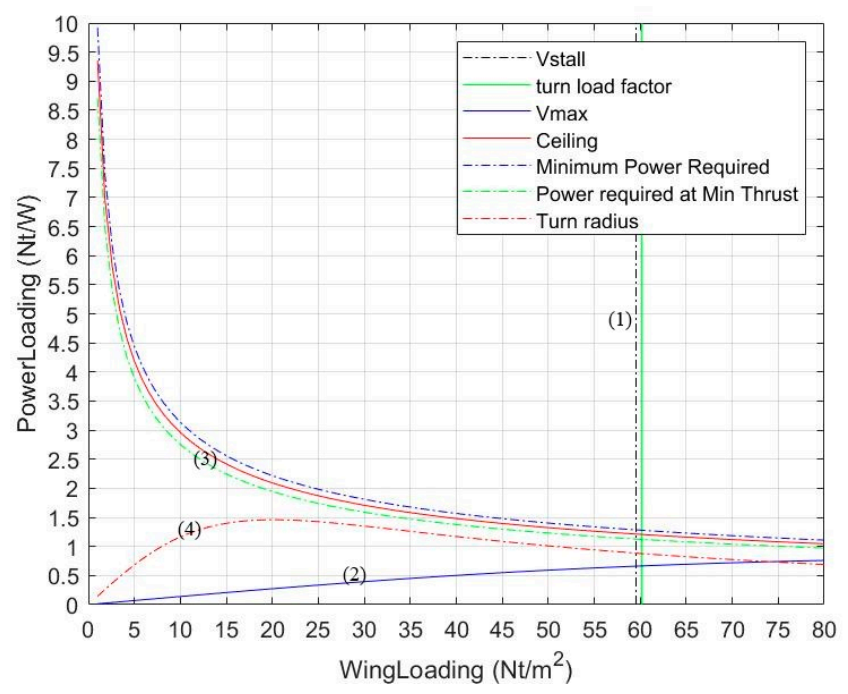

Figure 2. Matching plot for design of an experimental flying wing UAV.

The experimental flying wing UAV's performance can be summarized as follows:

1. The maximum lift coefficient is 1.2 and the stall speed at sea level is $9 \mathrm{~m} / \mathrm{s}$. The left area of the vertical black dashed line (1) in Figure 2 satisfies the stall speed.

2. At cruising altitude $(100 \mathrm{~m})$, the cruising speed is 1.15 times the maximum lift-to-drag ratio speed and the maximum speed is 1.2 times the cruising speed. The area below the blue solid line (2) in Figure 2 satisfies the requirement of the maximum speed at cruising altitude.

3. The absolute ceiling is $500 \mathrm{~m}$. The absolute ceiling demand is achieved by the area below the red solid line (3) in Figure 2.

4. At cruising altitude $(100 \mathrm{~m})$, the turn radius is $15 \mathrm{~m}$ at speed of $10 \mathrm{~m} / \mathrm{s}$. The area below the purple dashed line (4) in Figure 2 satisfies the requirement of the turning radius at a specific speed $(10 \mathrm{~m} / \mathrm{s})$ at cruising altitude.

\section{Weight Estimation for an Electric UAV}

The next step in the conceptual design is to estimate the total weight of the UAV. We proposed that the battery weight of the electric UAV could be estimated based on the UAV's endurance and range.

The total weight of an electric UAV can be divided into three parts: empty weight $\left(W_{E m p t y}\right)$, battery weight $\left(W_{\text {Battery }}\right)$, and payload weight $\left(W_{\text {Payload }}\right)$. The battery weight is derived based on the estimated endurance and range requirements.

The empty weight $\left(W_{E m p t y}\right)$ includes the structure, power system, and avionics system, which can be assumed as a function of the wing area. It can be calculated as:

$$
W_{\text {Empty }}=\rho_{\text {Empty }} * S
$$

where the empty mass density per wing surface area $\left(\rho_{\text {Empty }}\right)$ can be obtained from previous manufacturing experience. 


\subsection{Battery Weight Estimation with Endurance Requirement}

The electric-powered UAV's endurance mainly depends on its power consumption and battery. Its endurance is optimal for minimum power consumption. We use the minimum power consumption to estimate the battery weight. The battery mass $M_{\text {battery }}$ is calculated as:

$$
M_{\text {battery }}=\frac{E_{\text {battery }}}{\rho_{\text {battery }}}
$$

The energy density of the battery $\left(\rho_{\text {battery }}\right)$ selected in this design is $243 \mathrm{Wh} / \mathrm{kg}$. According to the conservation of energy, the aircraft's power consumption should be equal to the variation of battery energy during flight.

$$
\frac{d E_{B}}{d t}=-\frac{\left(\frac{P_{R_{\text {Min }}}}{\eta_{\text {motor }} \eta_{\text {propeller }}}+P_{\text {others }}\right)}{\eta_{\text {discharge }}}
$$

Assuming $P_{\text {others }}=0.1 \cdot P_{R M i n}$, the amount of aircraft power required between the start and end of flight includes take off and climb.

Therefore, the relation between battery energy and minimum power required $P_{R M i n}$ is:

$$
-E_{B_{0}} f_{\text {DoD }}=-\frac{1.1 P_{R_{\text {Min }}}}{\eta_{\text {motor }} \eta_{\text {propeller }} \eta_{\text {discharge }}} T_{\text {cruise }}
$$

where the depth of discharge $\left(f_{D o D}\right)$ indicates the percentage of the battery that has been discharged relative to the overall capacity of the battery. From the definition of the energy density of the battery, the battery weight in consideration of endurance can be estimated by dividing the battery power density to obtain as follows:

$$
\begin{gathered}
W_{\text {battery }}=\frac{1.1 P_{R_{\text {Min }}}}{\eta_{\text {motor }} \eta_{\text {propeller }} \eta_{\text {discharge }} f_{\text {DoD }} \rho_{\text {battery }}} T_{\text {cruise }} \\
P_{R_{\text {MIN }}}=\sqrt{\frac{2 W_{\text {Total }}^{3}}{\rho_{\infty} S_{\text {ref }}}}\left\{\frac{C_{L}^{3 / 2}}{C_{D}}\right\}_{\text {MAX }}=\sqrt{\frac{2 W_{\text {Total }}^{3}}{\rho_{\infty} S_{\text {ref }}}}\left\{\frac{C_{L}^{3 / 2}}{C_{D_{0}}+K C_{L}^{2}}\right\}_{\text {MAX }}
\end{gathered}
$$

where the minimum power required for a propeller-driven aircraft $\left(P_{R M i n}\right)$ occurs when $\left(C_{L}{ }^{3 / 2} / C_{D}\right)$ is maximum [5].

Therefore, the weight of battery in terms of wing loading, zero-lift drag coefficient, induced drag factor and endurance required is given.

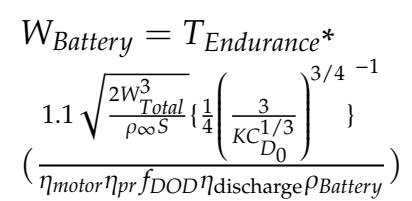

\subsection{Battery Weight Estimation with Range Requirement}

The electric-powered UAV's range is optimal when the required thrust is minimum. The derivative of the battery energy with respect to range is expressed as:

$$
\frac{d E_{B}}{d S}=-\frac{T_{R_{\min }}}{\eta_{\text {motor }} \eta_{\text {pr }} \eta_{\text {discharge }}}=-\frac{W_{\text {Total }} \sqrt{4 C_{D_{0} K}}}{\eta_{\text {motor }} \eta_{\text {pr }} \eta_{\text {discharge }}}
$$


The total variation in the battery energy and range between the start and end of flight can be expressed as:

$$
\int_{E_{B_{0}}}^{E_{B_{1}}} d E_{B}=-\frac{W_{\text {Total }} \sqrt{4 C_{D_{0}} K}}{\eta_{\text {motor }} \eta_{\text {pr }} \eta_{\text {discharge }}} \int_{R_{0}}^{R_{1}} d S
$$

Here, the left-hand side gives the total variation in battery energy between the start and end states. The right-hand side gives the total variation in range between the flight start position $R_{0}$ and flight end position $R_{1}$, and it can be expressed as:

$$
-\frac{W_{\text {Total }} \sqrt{4 C_{D_{0}} K}}{\eta_{\text {motor }} \eta_{\text {pr }} \eta_{\text {discharge }}} \int_{R_{0}}^{R_{1}} d S=-\left(\frac{W_{\text {Total }}}{\eta_{\text {motor }} \eta_{\text {pr }} \eta_{\text {discharge }}} \sqrt{4 C_{D_{0}} K}\right) R
$$

Therefore, the battery mass fraction of the aircraft's total weight for optimal range can be expressed as:

$$
\frac{\mathrm{W}_{\text {Battery }}}{W_{\text {Total }}}=\left(\frac{R \sqrt{4 C_{D_{0}} K}}{\eta_{\text {motor }} \eta_{\text {pr }} \eta_{\text {discharge }} \rho_{\text {battery }}}\right)
$$

\subsection{Weight Estimation for a Specific Payload and Endurance}

In this study, the payload is $2.5 \mathrm{~kg}$ and endurance is $3.5 \mathrm{~h}$. We obtain the total UAV weight for a given payload and endurance. The constant 1.1 in Equation (17) assumes that the power consumption of the avionics system in flight is $10 \%$ of the cruise consumption.

Table 1 lists the symbols from these equations and their values. The induced drag factor and zero-lift drag coefficient can be temporarily set as the empirical values obtained from the first calculation; these values are recalculated when the aerodynamic design is completed. Therefore, the total UAV weight can be expressed as:

$$
\begin{aligned}
& W_{\text {total }}=W_{\text {Empty }}+W_{\text {Battery }}+W_{\text {Payload }} \\
& =\rho_{\text {Empty }} S+W_{\text {Payload }}
\end{aligned}
$$

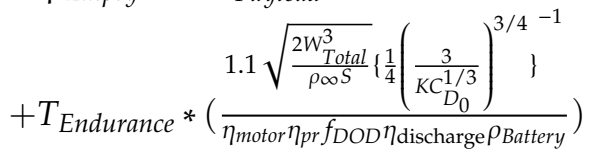

Table 1. Symbols and their values for weight estimation for a specific payload and endurance.

\begin{tabular}{ccc}
\hline Parameter & Symbol & Value \\
\hline Propeller efficiency & $\eta_{\operatorname{lr}}$ & 0.7 \\
Motor Efficiency & $\eta_{\text {motor }}$ & 0.8 \\
Battery Discharge Efficiency & $\eta_{\text {discharge }}$ & 0.95 \\
Empty mass density per Wing & $\rho_{\text {Empty }}$ & $2.44 \mathrm{Kg} / \mathrm{m}^{2}$ \\
Surface Area & $f_{D O D}$ & $23.91 \mathrm{Nt} / \mathrm{m}^{2}$ \\
Depth of Discharge & $\rho_{\text {Battery }}$ & $243(\mathrm{Wh} / \mathrm{Kg})$ \\
Battery Power density & $24.80(\mathrm{Wh} / \mathrm{Nt})$ \\
\hline
\end{tabular}

Assuming that the payload, endurance, and empty mass density per wing surface area are given, the total weight can be estimated as:

$$
W_{\text {total }}=\frac{W_{\text {Payload }}}{\left(1-\frac{\rho_{\text {Empty }}}{W_{\text {Total }} / S}-T_{\text {Endurance }} *\left(\frac{1.1 \sqrt{\frac{2 W_{\text {Total }}}{\rho_{\infty} S}}\left\{\frac{1}{4}\left(\frac{3}{\eta_{\text {motor }} \eta_{\text {pr }} f_{\text {DOD }} \eta_{\text {discharge }} \rho_{\text {Battery }}^{1 / 3}}\right)^{3 / 4}\right\}^{-1}}{N^{\prime}}\right)\right.}
$$


The payload is $2.5 \mathrm{~kg}$, the endurance is $3.5 \mathrm{~h}$, and the empty mass density per wing surface area is $2.44 \mathrm{~kg} / \mathrm{m}^{2}$. The estimated total weight of the electric UAV is $6.5 \mathrm{~kg}$, empty weight is $2.62 \mathrm{~kg}$, and battery weight is $1.38 \mathrm{~kg}$.

\section{Aircraft Aerodynamic and Stability Design}

Aircraft aerodynamic design focuses on the design of the wing and stability design and on the problem of flight stability. The wing is considered the most important component of the aircraft, and it strongly influences the aircraft's performance. The wing generates a lift force to balance the aircraft's weight. When doing so, it also has a drag force and pitching moment. Aeronautical engineering aims to maximize the wing's lift and minimize its drag and pitching moment. When the summation of all forces exerted on an aircraft and the summation of all moments about an aircraft's center of gravity is zero, the aircraft is said to be in trim or stable condition. In this section, we start with aerodynamic configuration and stability design and develop a design for an experimental flying wing UAV.

\subsection{Aerodynamic Configuration and Stability Design}

In aerodynamic configuration and stability design, the wing configuration greatly influences the aircraft's aerodynamic characteristics and efficiency. It is necessary to understand the wing and airfoil parameters to ensure that the aircraft has good aerodynamic characteristics under mission requirements. In this section, the aerodynamic configuration design is presented. Wing planform and airfoil selection are both important procedures in aerodynamic configuration design. The airfoil is designed to generate a suitable pressure distribution on the wing's top and bottom surfaces to maximize the lift and minimize the drag and pitching moment. The following parameters are important in airfoil selection: (1) the maximum lift coefficient (as large as possible); (2) the drag coefficient corresponding to the designed lift coefficient (as small as possible); (3) the corresponding drag coefficient should not change greatly near the design lift coefficient; and (4) the moment coefficient should not be too large and should be easy to trim.

The aerodynamic design of a wing mainly involves determining a wing planform that can maximize the lift and minimize the drag. The main planform parameters are the aspect ratio, sweep angle, and taper ratio. The aspect ratio affects the induced drag coefficient, zero-lift drag coefficient, and slope of lift coefficient. An increase in the aspect ratio can reduce the wing's induced drag. A decrease in the aspect ratio prevents wing tip stall under high angle of attack and reduces the wing structure's weight and the bending moment at the wing root.

The wing's induced drag is related to the induced drag factor that is in turn affected by the lift coefficient. When the lift coefficient increases, the wing's induced drag also increases. An increase in the aspect ratio can decrease the induced drag factor. An elliptical wing has the lowest induced drag factor; however, it is not easy to manufacture. The induced drag factor can be adjusted with appropriate planform parameters. In this study, the wing is designed to reduce the induced drag with a tapered ratio. The root chord is $0.54 \mathrm{~m}$, tip chord is $0.22 \mathrm{~m}$, wingspan is $2.83 \mathrm{~m}$, and aspect ratio is 7.48 .

Fuselage design mainly considers the internal space, and fuselage drag should be minimized. For a low-speed experimental flying wing UAV, the internal space configuration and manufacturing costs are the main considerations. The aerodynamic configuration design of the fuselage is not as important.

Wings with large sweep angles are commonly designed for aircrafts that fly at high speeds. The wing's critical Mach number can be increased by increasing the sweep angle. Although the experimental flying wing UAV flies at low speed, we design the wing with a sweep angle that satisfies the aircraft's static stability requirements. To increase the flying wing UAV's lateral stability, its dihedral angle is designed suitably.

\subsection{Design of Experimental Flying Wing $U A V$}

The matching plot is used to obtain the appropriate wing loading and power loading, and the maximum take-off weight is formulated and estimated in the weight estimation approach. Then, 
the energy consumption and wing reference area of the aircraft are obtained. The estimated total weight of the electric-powered UAV is $6.5 \mathrm{~kg}(63.7 \mathrm{Nt})$, and the maximum energy consumption calculated from a power loading of $0.5887 \mathrm{Nt} / \mathrm{W}$ is $102 \mathrm{~W}$. Based on the motor specifications [19], the AXi 4130/20 kv305 electric brushless motor (Figure 3a) is sufficient to provide the required power.

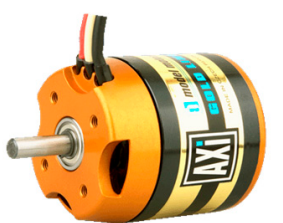

(a)

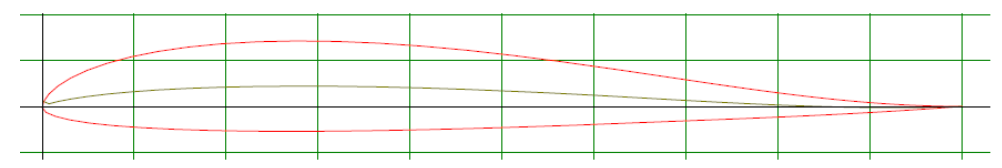

(b)

Figure 3. (a) AXi 4130/20 kv305 brushless electric motor and (b) s5010 airfoil profile.

Aircraft aerodynamics and stability design starts with the given wing reference area. Then, the aircraft's shape and configuration are determined. Considering aerodynamic and static stability requirements, a Selig S5010 low-Reynolds-number airfoil is selected. Aerodynamic design consists of selecting the appropriate wing planform, aspect ratio, sweep angle, twist angle, and dihedral angle to meet the aircraft's requirements. The induced drag factor and zero lift drag coefficient are fed back for performance calculation and weight estimation. Stability design provides an appropriate center of mass to meet the static stability requirements.

For a wing load of $59.53 \mathrm{Nt} / \mathrm{m}^{2}$ and total weight of $63.7 \mathrm{Nt}$ (total mass of $6.5 \mathrm{~kg}$ ), the wing area is calculated to be $1.07 \mathrm{~m}^{2}$; aerodynamic design and static stability design are based on this wing area. Figure $3 \mathrm{~b}$ shows the $\mathrm{s} 5010$ airfoil profile. The aerodynamic characteristics are estimated using XFLR5 [17] and DATCOM software. The cruise speed is $17.6 \mathrm{~m} / \mathrm{s}$, root chord is $0.54 \mathrm{~m}$, tip chord is $0.22 \mathrm{~m}$, wingspan is $2.83 \mathrm{~m}$, aspect ratio is 7.48 , sweep angle is $30^{\circ}$, twist angle is $-4^{\circ}$, dihedral angle is $2^{\circ}$, and flight angle of attack is $4^{\circ}$.

XFLR5 and DATCOM software can be used to easily build a 3D model and estimate the aircraft's zero-lift drag coefficient and induced drag factor. When these parameters are obtained, we can check their variations to ensure that the empirical value obtained from the first calculation is appropriate. If the variations are smaller than desired, the design is considered complete. If the variations are larger than desired, the new zero-lift drag coefficient and induced drag factor of the aircraft are substituted into the next process. Figure $4 \mathrm{a}$ shows the $3 \mathrm{D}$ wing planform of the flying wing UAV. Figure $4 \mathrm{~b}$ shows the drag polar and that the induced drag coefficient $K=0.0516$ and zero-lift drag coefficient $=0.009$.

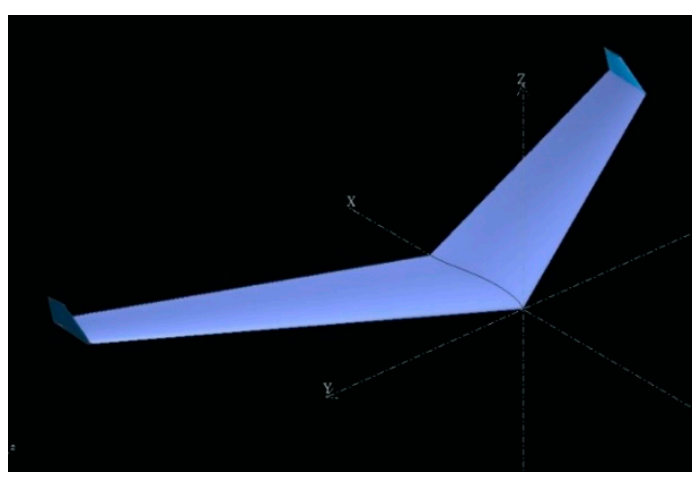

(a)

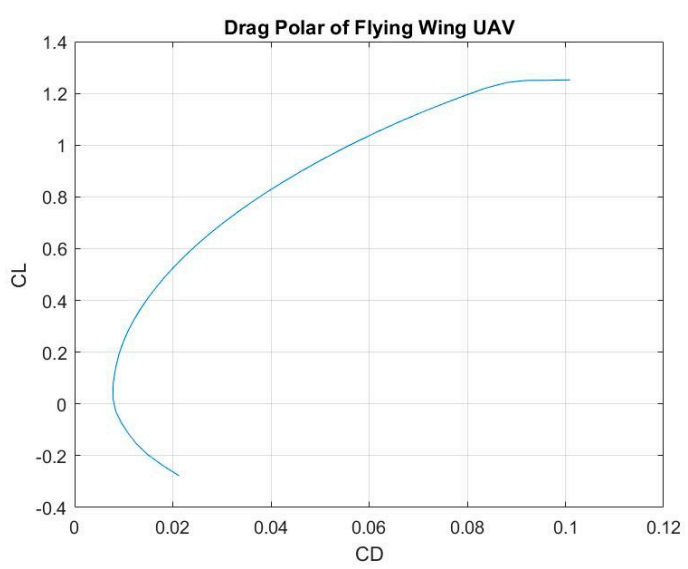

(b)

Figure 4. (a) 3D wing planform of flying wing UAV and (b) drag polar. 
To obtain proper stability, the center of mass of the whole machine is set at $0.439 \mathrm{~m}$ from the head and the static stability margin is $8.6 \%$. Figure 5 shows the relationship between the lift coefficient and the angle of attack and the relationship between the pitching moment coefficient and the angle of attack. At an angle of attack of $4^{\circ}$, the pitching moment coefficient is 0 and lift coefficient is 0.325 . Table 2 lists the main aerodynamic characteristics.

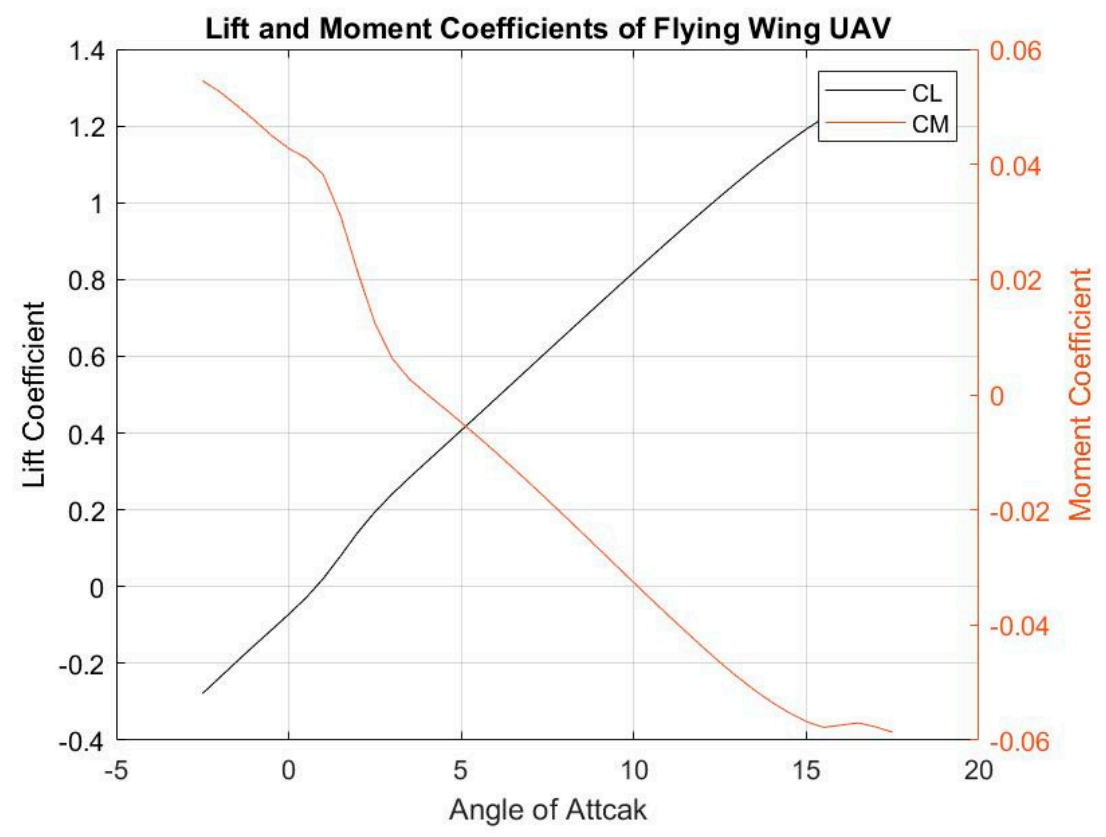

Figure 5. Relationship between the lift coefficient and the angle of attack and relationship between the pitching moment coefficient and the angle of attack.

Table 2. Main aerodynamic characteristics.

\begin{tabular}{ccc}
\hline Parameter & Symbol & Value \\
\hline Zero lift drag coefficient & $C_{D_{0}}$ & 0.009 \\
Induced drag factor & $K$ & 0.0516 \\
Cruising speed & $V$ & $17.6 \mathrm{~m} / \mathrm{s}$ \\
Maximum speed & $V_{\text {Max }}$ & $21.15 \mathrm{~m} / \mathrm{s}$ \\
Wing area & $\mathrm{A}$ & $1.07 \mathrm{~m}^{2}$ \\
Wing root chord & $\mathrm{Cr}$ & $0.54 \mathrm{~m}$ \\
Wing tip chord & $\mathrm{Ct}$ & $0.22 \mathrm{~m}$ \\
Wing span & $\mathrm{b}$ & $2.83 \mathrm{~m}$ \\
Wing aspect ratio & $\mathrm{AR}$ & 7.48 \\
Wing sweep angle & $\Lambda$ & $30 \mathrm{deg}$ \\
Wing twist angle & $\alpha_{\text {twist }}$ & $-4 \mathrm{deg}$ \\
Wing dihedral angle & $\Gamma$ & $2 \mathrm{deg}$ \\
Wing attack angle & $\alpha$ & $4 \mathrm{deg}$ \\
\hline
\end{tabular}

\section{Manufacturing Experimental Flying wing UAV}

Designers must select suitable materials during manufacturing. The experimental flying wing UAV can be manufactured using different methods. However, it is necessary to consider how to manufacture a firm and lightweight UAV that can meet all aerodynamic configurational requirements. Composite materials are preferable for this purpose. Therefore, the proposed flying wing UAV is manufactured using composite materials. The above-described conceptual design is validated and then the experimental flying wing UAV is manufactured.

Aerodynamic configuration design determines the aircraft size. However, the internal space and aircraft structure are not defined and designed. Aerodynamic configuration and mission requirements 
are important constraints of the detailed design. These constraints are specified through engineering drawings for the manufacturing processes. Engineering drawings must be prepared at the start for ensuring smooth manufacturing processes. Simultaneously, manufacturing cost and schedule should be considered carefully in the detailed design to manufacture the aircraft in time.

The engineering drawings also consider composite material manufacturing molds and assembly installation works. Once the engineering drawings are complete, the flying wing UAV's external and internal structures are well defined, as shown in Figure 6, and therefore, it is ready to manufacture.

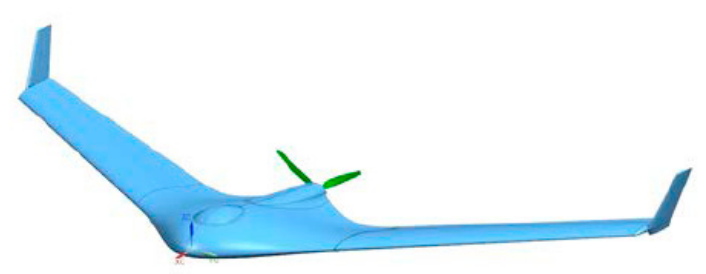

(a)

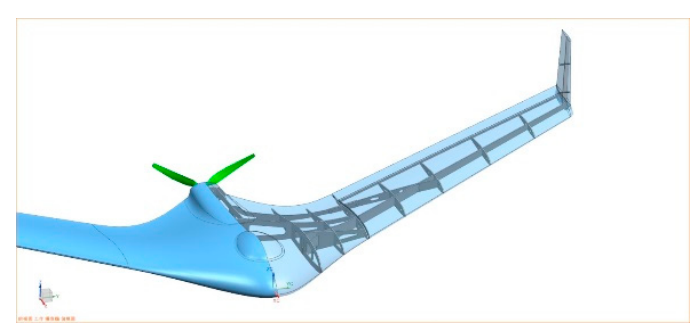

(b)

Figure 6. (a) External structure and (b) internal structure of flying wing UAV.

Based on the aerodynamic configuration and manufacturing and structural considerations, the flying wing UAV is divided into main and secondary structural modules. The main structural modules are the fuselage module and the left and right wing modules. The secondary structural modules are the left and right wing tip modules. The main structural modules must have certain structural strengths and be able to bear the forces generated during flight. If these modules are damaged during flight, a serious failure can occur. Therefore, these modules are crucial in system engineering and should be reviewed and checked before flight testing. Secondary structural modules are designed to adjust the lift distribution in the wingtip. If they suffer damage, a safe landing is still possible. The detailed design generally considers the structural strength and assembly tolerance of all modules. After the modules are designed and manufactured, if the module interfaces cannot be integrated together, the detailed design is adjusted or redesigned. The flying wing experimental UAV has a low weight and small size. Its aerodynamic configuration, manufacturing, and structural integration works are simpler than those of a commercial aircraft. Therefore, its detailed design could be handled by the Tamkang University (TKU) UAV team, although several adjustments were required. Figure 7 shows the main structural modules and secondary structural modules in the flying wing UAV.

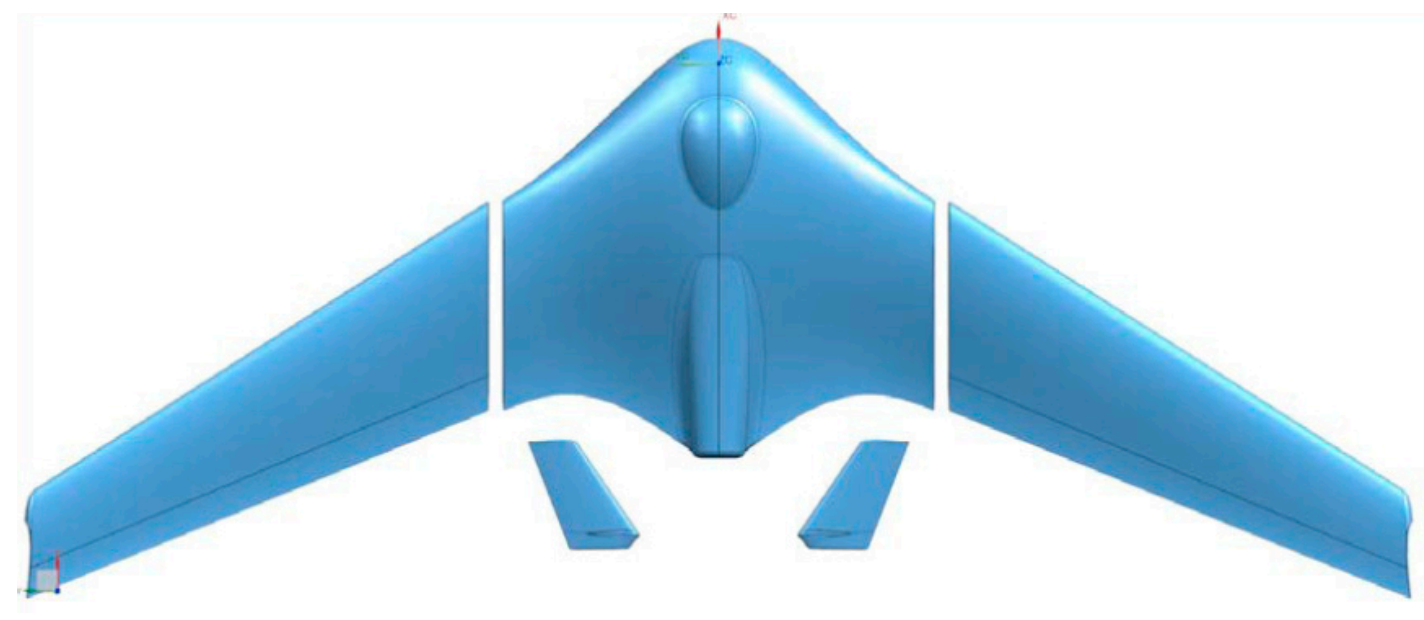

Figure 7. Main and secondary structural modules of flying wing UAV.

The size and shape of the aircraft cross section are governed by aerodynamic considerations and must be maintained for all loading generated by the flight environment. The fuselage and the left and 
right wing modules consist of numerous ribs and skins that together maintain the size and shape of the aircraft cross section and resist distributed aerodynamic pressure loads.

The ribs are made of balsa wood and are placed inside the fuselage, left wing, and right wing. The ribs are produced through laser cutting in light of the manufacturing cost and time. When all ribs are produced, they are preassembled to ensure the shape and size of the cross section. Figure 8 shows an engineering drawing of the ribs and the preassembly of the ribs.

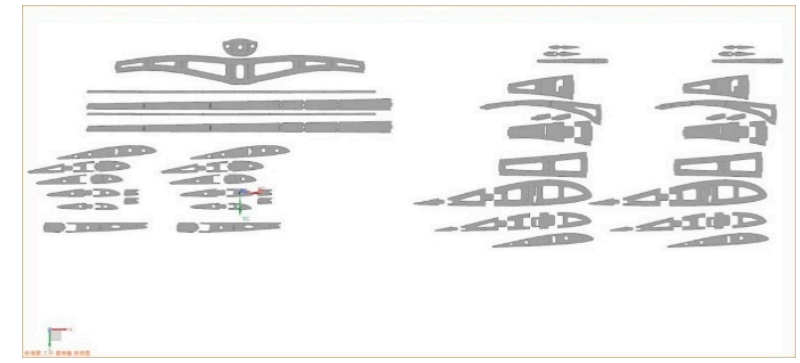

(a)

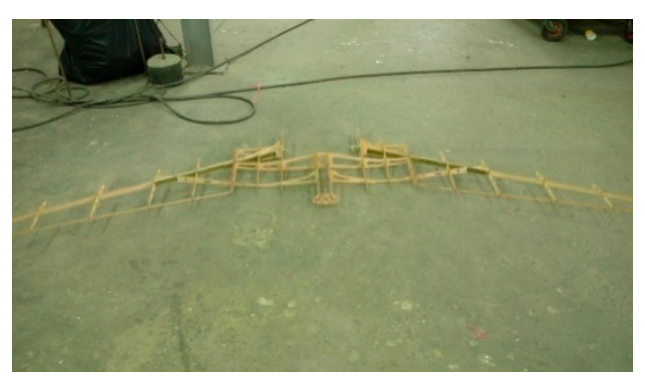

(b)

Figure 8. (a) Engineering drawing of ribs and (b) preassembly of ribs.

The skin provides an impermeable surface for maintaining the air pressure distribution on the wing. It is made of composite materials, specifically, carbon fiber and epoxy resin composites that were fabricated using vacuum bagging and a hand lay-up method, to reduce the aircraft's structural weight. The mold and ribs must be produced before fabricating the skins.

Composite materials and medium-density fiberboard (MDF) molds are cheaper than aluminum or steel molds and were therefore designed and fabricated to make the skins of the flying wing UAV. The molds of composite materials consisted of Styrofoam, glass fiber, and epoxy resin. First, the Styrofoam pieces were cut to predesigned sizes. Then, the glass fiber and epoxy resin were adhered to the Styrofoam pieces. It should be noted that epoxy resin, and not polyresin, is used; when poly resin adheres to Styrofoam pieces, it can damage or dissolve the Styrofoam.

Figure 9 shows the predesigned size of the Styrofoam mold and the mold consisting of Styrofoam, glass fiber, and epoxy resin. Figure 10 shows the mold of the wing and the glass fiber and carbon fiber.

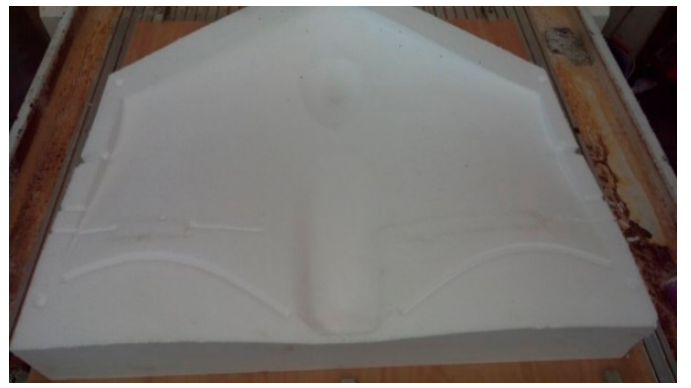

(a)

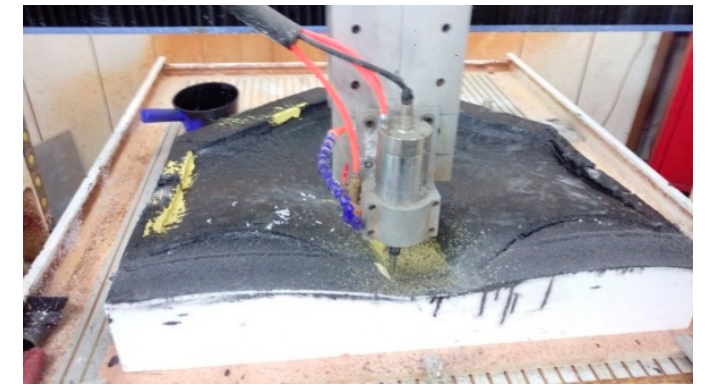

(b)

Figure 9. (a) Predesigned size of Styrofoam mold (fuselage) and (b) design size of mold consisting of Styrofoam, glass fiber, and epoxy resin (fuselage). 


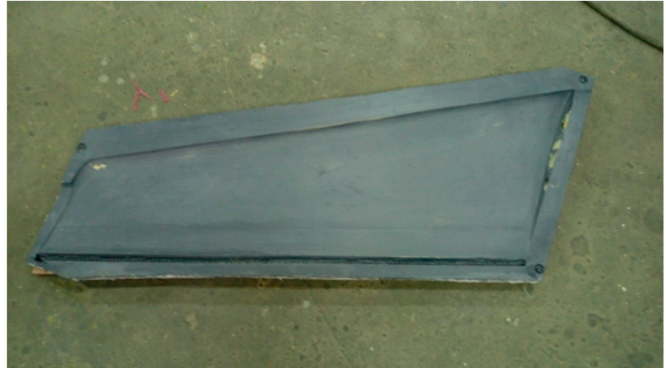

(a)

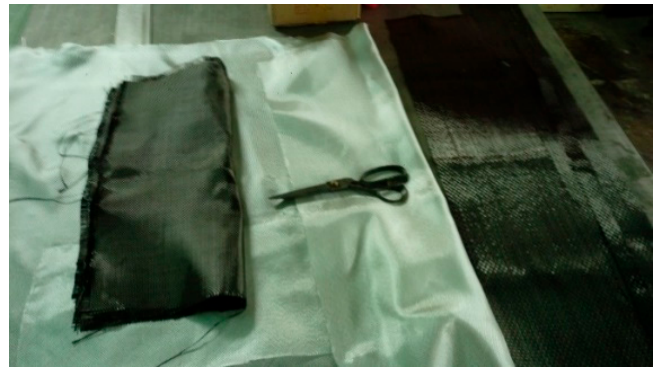

(b)

Figure 10. (a) Mold of the wing and (b) glass fiber and carbon fiber.

After the molds made of the composite materials are completed, hand lay-up and vacuum bag molding methods are used to fabricate the main and secondary structural modules. The three main and two secondary modules are finally assembled to complete the flying wing UAV. The hand lay-up method is suitable for making a wide range of composite products. Its manufacturing equipment is inexpensive. However, skilled operators are required to achieve good production and quality using this method.

In the study, carbon fiber, glass fiber, and epoxy resin are placed in an open mold and cured by exposure to air. This method is inexpensive and is suitable for manufacturing prototype products. In the vacuum bag molding method, the carbon fiber, glass fiber, and epoxy resin are placed in the bag to form the shape. Then, a pump is used to gradually create a vacuum in the bag. This approach removes air and eliminates excess resin, resulting in more favorable mechanical properties.

Figure 11a shows the hand lay-up and open molding method. Figure 11b shows the vacuum bag molding method. Figure 12 shows the upper mold of the fuselage with ribs and the main structural modules (fuselage).

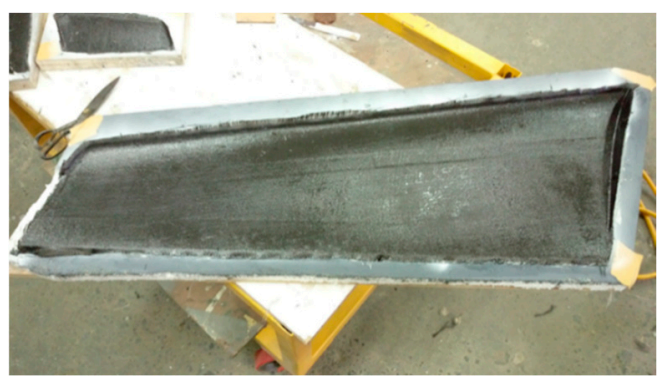

(a)

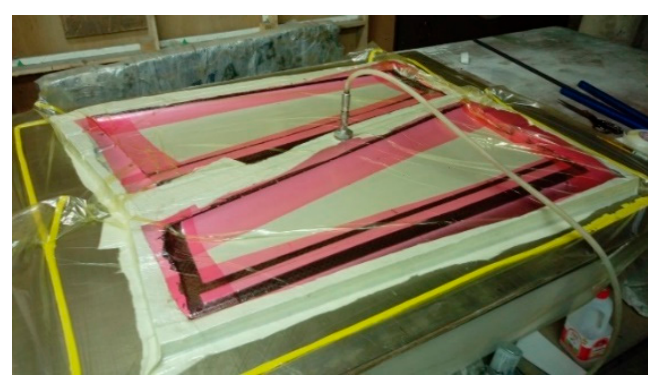

(b)

Figure 11. (a) Hand lay-up and open molding method and (b) vacuum bag molding method.

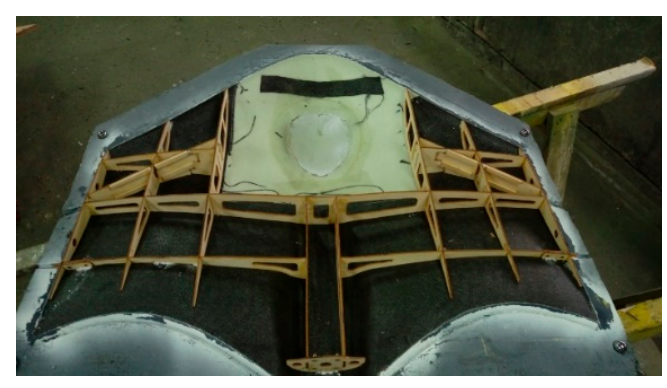

(a)

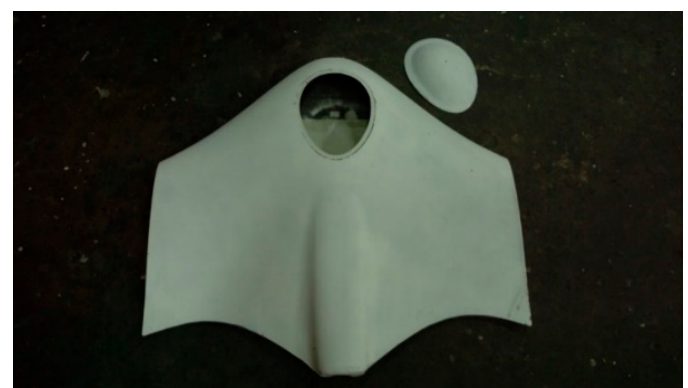

(b)

Figure 12. (a) Upper mold of the fuselage with ribs and (b) main structural modules (fuselage).

Once the main and secondary structural modules are completed, they are assembled to form the experimental flying wing UAV. The skin is made of carbon fiber, glass fiber, and epoxy resin, and the 
ribs are made of balsa wood. The wingspan is $3.0 \mathrm{~m}$, fuselage is $1.2 \mathrm{~m}$, and structural weight is $6 \mathrm{~kg}$. Figure 13 shows the main and secondary structural modules and the completed experimental flying wing UAV. Propulsion power is provided by an AXi 4130/20 kv305 electric brushless motor. Pixhawk is used as the flight control system. A polymer battery pack $(2 \times 5000 \mathrm{mAh})$ with a total weight of $8.62 \mathrm{~kg}$ is also used.

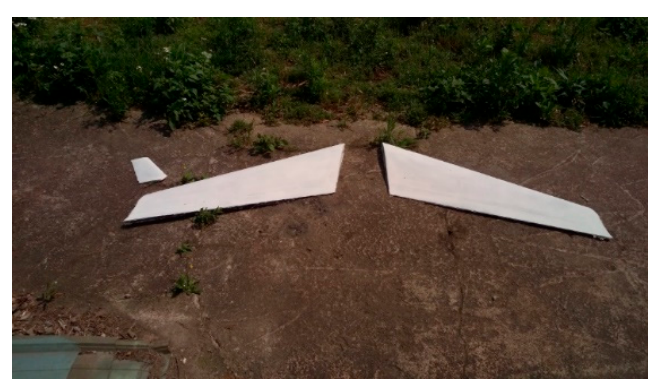

(a)

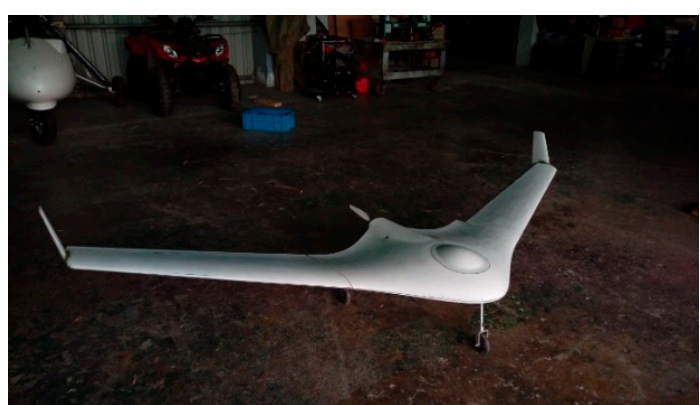

(b)

Figure 13. (a) Main structural modules (left and right wings) and secondary structural modules (wing tip) and (b) experimental flying wing UAV.

\section{Flight Test}

The experimental flying wing UAV consists of a propulsion system, flight control and navigation system, battery pack, main and secondary structural modules, control surface actuators, and a ground control station. The propulsion system consists of an AXi 4130/20 kv305 electric brushless motor and a $15.5 \times 12$ four-blade propellers. Pixhawk 4 (PX4), a low-cost autopilot software, is used as the flight control and navigation system [20]. PX4 has an IMU module (gyroscopes and accelerometers), magnetometer (compass), barometer, GPS module, power system, and various interfaces (e.g., PWM, general-purpose serial ports, I2C, SPI buses, CANBuses, R/C input). It can handle all flight control and navigation requirements of the experimental flying wing UAV. PX4 has a weight of $15.5 \mathrm{~g}$, dimensions of $44 \times 84 \times 12 \mathrm{~mm}$, and operating temperature of $-40{ }^{\circ} \mathrm{C}$ to $85^{\circ} \mathrm{C}$. The battery pack is $1.6 \mathrm{~kg}$, and then the total weight of the experimental flying wing UAV is $8.62 \mathrm{~kg}$. The total weight of the actual UAV exceeds the original design weight of $6.5 \mathrm{~kg}$. If the payload is not loaded, the cruising speed increases to $20.3 \mathrm{~m} / \mathrm{s}$, and this requires a power of $77 \mathrm{~W}$.

According to flight test guidelines [21], the flight test is conducted without the payload. The flight test consists of two phases. The first phase involves remote control by a pilot $\mathrm{R} / \mathrm{C}$ direct command in the planned flight condition. Flight in the first phase is observed and evaluated by a pilot. The first phase of the flight test clarifies the basic performance. The second phase involves remote control governed by PX4 without a pilot R/C direct command; the flight attitude is determined by PX4 using the gyroscopes and accelerometers to analyze the aircraft's dynamic characteristics. Flight tests are performed to measure and evaluate the UAV's characteristics during flight and to verify that these characteristics are as desired. Proper preparations and inspections help ensure that the UAV is ready to fly and contribute toward an efficient, productive, and safe flight test program.

Before the first flight test, the flight plan must be reviewed carefully. When all flight preparations and inspections were completed and the weather was within acceptable limitations, the first flight test was performed at 2 pm on 29 May 2018, in New Taipei City. It followed a typical airfield traffic pattern, that is, a standard path followed by an aircraft when taking off or landing while maintaining visual contact with the airfield. Such patterns are used at airfields for air safety. Owing to the use of a consistent flight pattern, pilots will know from where to expect other air traffic and be able to see and avoid it. When pilots fly under visual flight rules (VFRs), the airfield traffic pattern is vital in keeping things orderly and safe. Figure 14 shows a typical airfield traffic pattern [22]. 


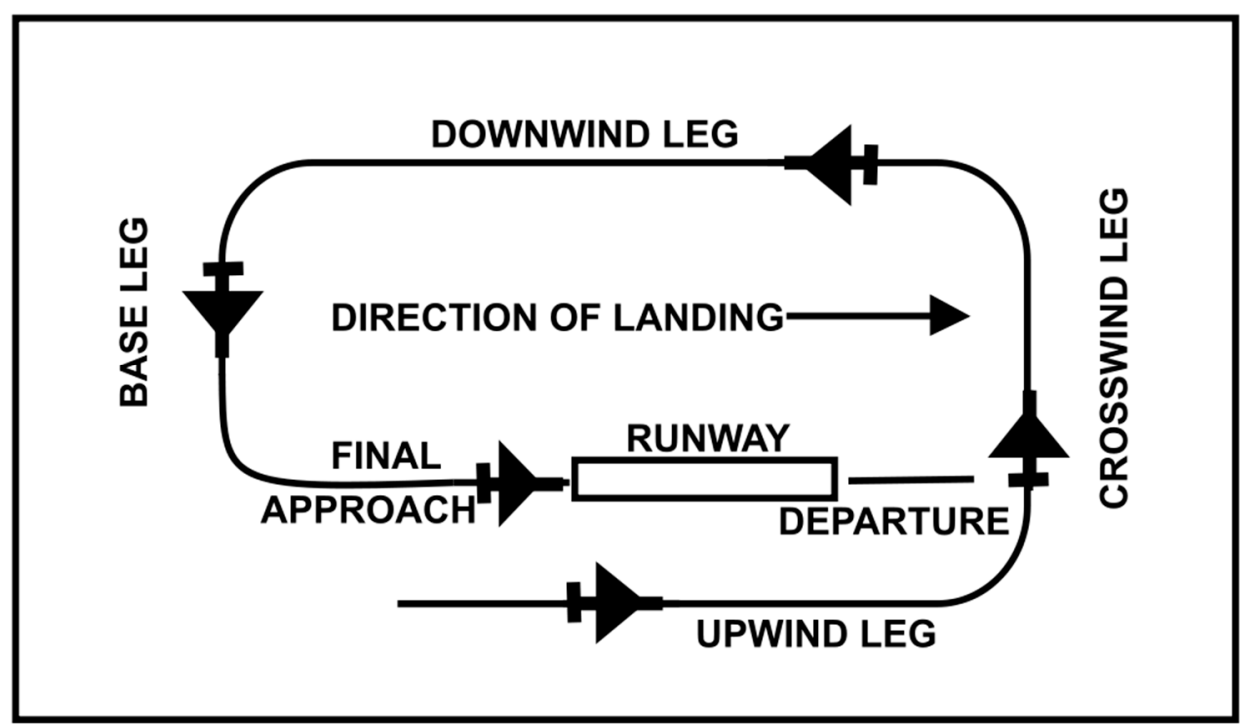

Figure 14. A typical airfield traffic pattern.

The battery pack was charged fully at first, and then, the primary control test was performed. This test is an important inspection for the UAV. The primary control of the flying wing UAV involves the throttle and the elevons to control the pitch and roll. These main control commands are transmitted by a remote controller. When the throttle command is tested, the aircraft must be firmly fixed on the ground to avoid injury to people. Control surface commands are transmitted to the servo system that consists of servo and control surfaces, and every control surface must move smoothly.

According to the flight plan, the flying wing UAV was positioned at the start of the runway. Its direction of flight was into the wind, and the throttle command was set to the maximum. The airplane accelerated along the ground, and we tried to keep it going in a straight line along the runway at all times. Owing to the risk, the first flight test was not attempted in crosswind. As the speed approached the take-off speed, we used elevon commands to make the UAV take off from the ground. If these commands are given before the UAV reaches take-off speed, the climb rate may become large and cause the UAV to stall.

When the UAV took off, it flew smoothly. It climbed to a height of 20-30 m, following which we gently decreased the throttle to an intermediate level. Then, we turned the UAV left and kept level flight. After turning to level flight, we gave the ailerons commands in trim, and the UAV remained stable in level flight. For landing, when the UAV was in the baseleg before the final approach, the throttle command was decreased smoothly. At the final approach, the throttle command was decreased to zero for landing. Even when the throttle command was decreased to zero, the UAV's speed was too high during the first landing. Therefore, we decided to fly all routes in the flight plan again to understand the UAV's performances and characteristics. After several attempts, we managed a landing that, though not perfect, did not cause any damage. After landing, we thought of installing a brake system in the UAV to decrease its speed.

After the first flight test, the pilot gained a basic understanding of the UAV's performance and characteristics. The second flight test was aimed at obtaining the flight attitude using gyroscopes and accelerometers in PX4 to analyze the UAV's dynamic characteristics. These data were evaluated to verify that the performance and characteristics were as desired. A second flight plan and inspections were performed, and the second flight was performed on 6 July 2018, at the same place. Two flight test missions were planned to obtain more flight data. The flight data record was uploaded to the PX4 flight review and included in the Supplementary Materials in the paper. The second flight data includes flight trajectories, airspeed, ground speed, and attitude angle.

From these flight data, we verified the relationship between the UAV's total weight and stall speed. First, we discussed why the stall speed in the flight test differed from that in the previous 
design. The UAV's stall speed was approximately $11 \mathrm{~m} / \mathrm{s}$ in the first round of the second flight test. As mentioned above, the total weight of the originally designed UAV is $6.5 \mathrm{~kg}$ and that of the actual $\mathrm{UAV}$ is $8.62 \mathrm{~kg}$. The actual total weight was 1.33 times the original design weight. With the actual total weight, the estimated stall speed was $10.4 \mathrm{~m} / \mathrm{s}$; this was close to the speed measured in the flight test. Figures 15 and 16 respectively show the airspeed and attitude in the first round of the second flight test. In Figure 16, the left-hand-side vertical axis shows the pitch and roll angle, and the right-hand-side vertical axis shows the yaw angle.

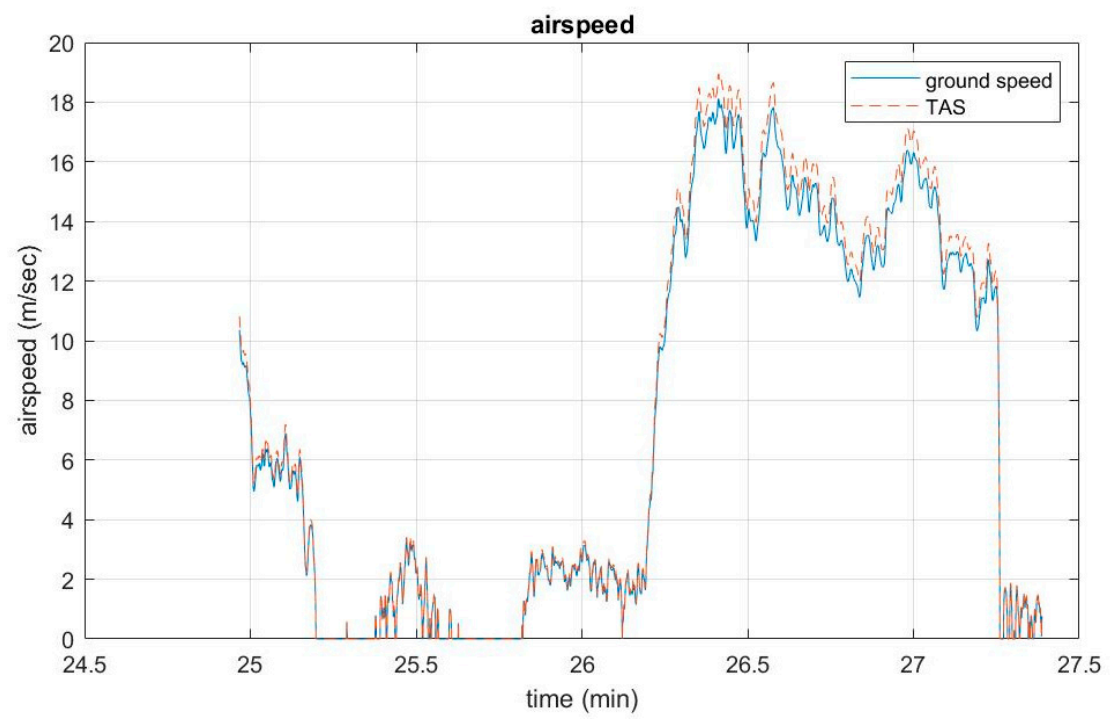

Figure 15. Airspeed in the first round of the second flight test (time $=24.5-27.5 \mathrm{~s}$ ).

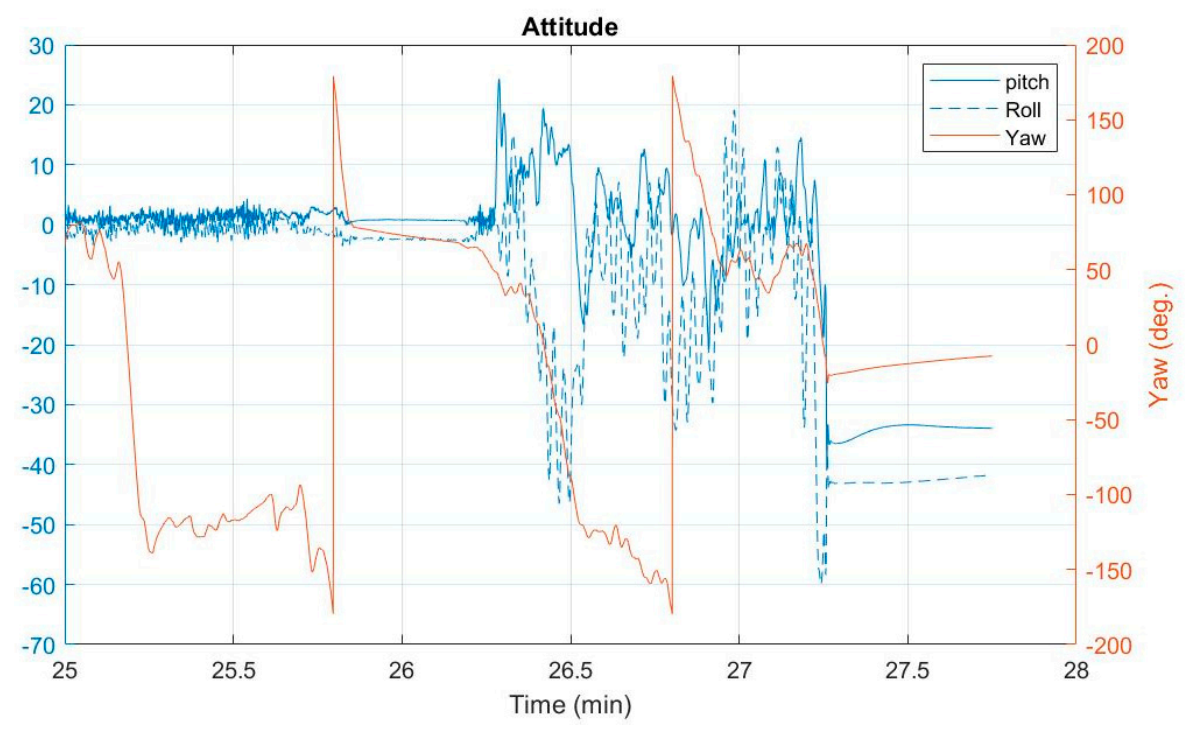

Figure 16. Attitude in the first round of the second flight test (time $=25-28 \mathrm{~s}$ ).

The second round began 5 min after the first round of the second flight test. Although flight data was obtained in this round, the UAV was damaged slightly during landing. Specifically, its left main landing gear broke because of the hard landing. The maximum airspeed was $19.3 \mathrm{~m} / \mathrm{s}$ (at $34 \mathrm{~min}$ ); this was lower than the estimated cruise speed of $20.3 \mathrm{~m} / \mathrm{s}$. This reveals that the propulsion system cannot provide sufficient power for the maximum speed of the UAV. The electric brushless motor's output power may be insufficient for a UAV weight of $8.62 \mathrm{~kg}$. Therefore, the UAV did not reach the maximum designed airspeed. Figures 17 and 18 respectively show the airspeed and attitude in the second round of the second flight test. 


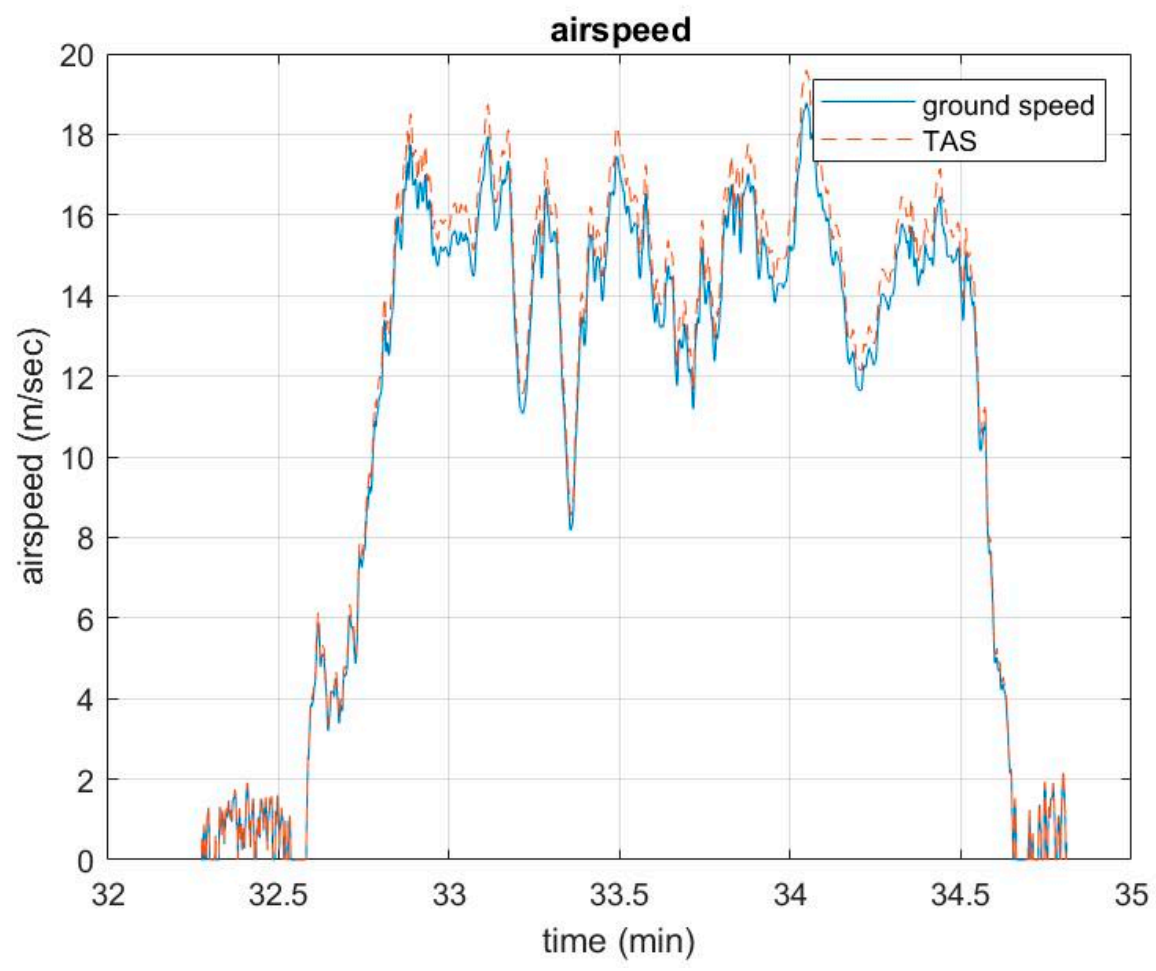

Figure 17. Airspeed in the second round of the second flight test (time $=32-35 \mathrm{~s}$ ).

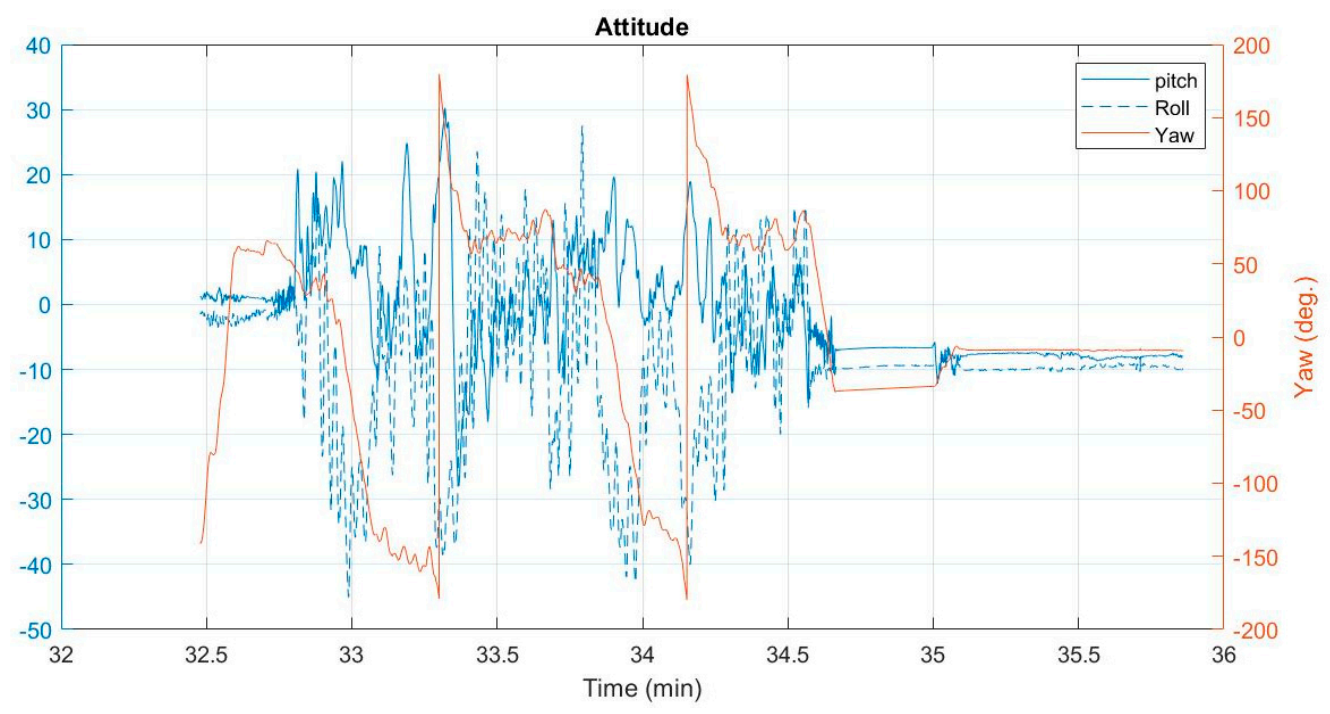

Figure 18. Attitude in the second round of the second flight test (time $=32-36 \mathrm{~s}$ ).

\section{Discussion}

This paper reports the design, manufacturing, and testing of an experimental flying wing UAV. The major achievements of this study include the aerodynamic performance design based on the matching plot, weight estimation approach, and conventional aircraft design procedures. By using the matching plot, the appropriate wing loading and power loading that can satisfy all performance requirements are determined clearly. By using the weight estimation approach, the aircraft's empty structure mass is parameterized as a function of the wing reference area. By using the parameterization results, the maximum take-off weight is formulated and estimated successfully. Design parameters such as the zero-lift drag coefficient and induced-drag factor are temporarily given empirical values from the first calculation and recalculated in the aerodynamic performance design procedure. The feedback of the 
zero-lift drag coefficient and induced-drag factor is terminated when the feedback values become similar to the initial ones. Strength analysis is not considered in this study. It will be included in our future work.

Based on the design results, an experimental flying wing UAV is then built. This is the TKU UAV laboratory's first attempt to perform the whole main structural assembly of the composite materials of an aircraft. After successfully assembling the main and secondary modules, necessary inspections and flight plans were completed, and the first flight test was performed on 29 May 2018. The actual total weight exceeds the original design weight of $6.5 \mathrm{~kg}$. This large error can be attributed to the ratio of the empty weight to wing reference area. The empirical value of this ratio was not sufficiently accurate in the weight estimation approach. This was mainly because this is our first attempt to manufacture the main structural assembly of an aircraft using composite materials. The empirical value should improve after gaining more manufacturing experience.

For a payload of $2.5 \mathrm{~kg}$, the maximum takeoff weight is $11.12 \mathrm{~kg}$ and wing load is $101.85 \mathrm{Nt} / \mathrm{m}^{2}$. The performance of our flying wing UAV is as follows.

1. The maximum lift coefficient is still assumed to be 1.2, and the stall speed at sea level is $11.77 \mathrm{~m} / \mathrm{s}$.

2. At cruising altitude $(100 \mathrm{~m})$, the cruising speed is $23.06 \mathrm{~m} / \mathrm{s}$ and cruising power is $113 \mathrm{~W}$. The maximum speed at cruising altitude is $25.36 \mathrm{~m} / \mathrm{s}$ and maximum power demand is $192 \mathrm{~W}$.

3. The absolute ceiling is still $500 \mathrm{~m}$.

4. At cruising altitude (100 m), the turning factor (load factor) is 1.21 , and the turning radius is $25.13 \mathrm{~m}$ at flight speed of $12.94 \mathrm{~m} / \mathrm{s}$.

Figure 19 shows the matching plot for the actual experimental flying wing UAV. The second flight test only recorded flight trajectory, airspeed, ground speed, and attitude angle, and limited analysis of the data was conducted after the flight experiment.

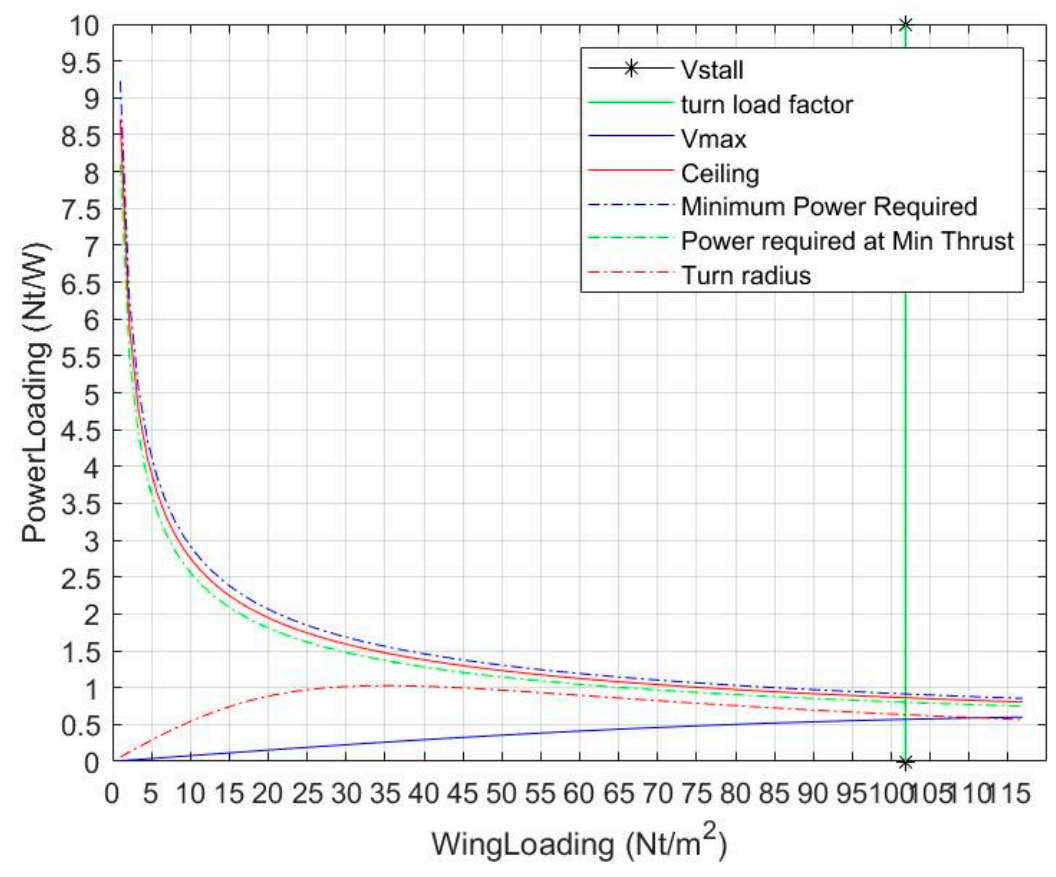

Figure 19. Matching plot for actual experimental flying wing UAV. 
Supplementary Materials: The flight data record was uploaded to the PX4 flight review at https://review.px4.io/ upload, and it can be found at https://review.px4.io/plot_app?log=d78a4212-fd7b-43d5-a92d-0887ec4ac78a.

Author Contributions: Conceptualization, P.-H.C. and D.-M.M.; methodology, P.-H.C. and D.-M.M.; formal analysis, P.-H.C. and D.-M.M.; investigation, D.-M.M. and J.-K.S.; validation, D.-M.M. and J.-K.S.; writing-original draft preparation, P.-H.C. and D.-M.M.; writing-review and editing, D.-M.M. and J.-K.S.; supervision, D.-M.M. and J.-K.S.; project administration, D.-M.M. and J.-K.S.; funding acquisition, D.-M.M. and J.-K.S.

Funding: This research was funded by the Ministry of Science and Technology, Taiwan, under Grant MOST

Acknowledgments: Thanks to CASI Aero Industries Ltd. for providing venues and equipment to build the experimental flying wing UAV. The authors are also grateful to the graduate students for the discussion of the performance differences between the actual total weight and the original design in the 2018s semester course (Aircraft Performance Analysis).

Conflicts of Interest: The authors declare no conflict of interest.

\section{References}

1. Goraj, Z. Design Challenges Associated with Development of a New Generation UAV. Aircr. Eng. Aerosp. Technol. 2005, 77, 361-368. [CrossRef]

2. Cambone, S.A.; Krieg, K.J.; Pace, P.; Wells, L., II. Unmanned Aircraft Systems Roadmap 2005-2030; U.S. Dept. of Defense: Washington, DC, USA, 2005.

3. Roskam, J. Airplane Design: Part I; Roskam Aviation and Engineering Corp.: Ottawa, KS, USA, 1989.

4. Mohammad, H.S. Aircraft Design: A Systems Engineering Approach; John Wiley \& Sons Ltd.: West Sussex, UK, 2013.

5. Anderson, J.D., Jr. Aircraft Performance and Design; McGraw-Hill: New York, NY, USA, 1999.

6. Loftin, L.K. Subsonic Aircraft: Evolution and the Matching of Size to Performance; NASA Reference Publication 1060: Washington, DC, USA, 1980.

7. Gokcin, C.; Mathias, E.; Dimitri, N.M. A Methodology for Sizing and Analysis of Electric Propulsion Subsystems for Unmanned Aerial Vehicles. In Proceedings of the 54th AIAA Aerospace Sciences Meeting, AIAA SciTech Forum, San Diego, CA, USA, 4-8 January 2016. [CrossRef]

8. Traub, L.W. Range and Endurance Estimates for Battery-Powered Aircraft. J. Aircr. 2011, 48, $703-707$. [CrossRef]

9. Giulio, A.; Fabrizio, G. Maximum Range for Battery-Powered Aircraft. J. Aircr. 2013, 50, 304-307.

10. Ostler, J.N.; Bowman, W.J.; Snyder, D.O.; McLain, T.W. Performance Flight Testing of Small Electric Powered Unmanned Aerial Vehicles. Int. J. Micro Air Veh. 2009, 1, 155-171. [CrossRef]

11. Brandt, S.A.; Gilliam, F.T. Design Analysis Methodology for Solar-Powered Aircraft. J. Aircr. 1995, 32, 703-709. [CrossRef]

12. Shiau, J.K.; Ma, D.M.; Shie, J.R.; Chiu, C.W. Optimal Sizing and Cruise Speed Determination for a Solar-Powered Airplane. J. Aircr. 2010, 47, 622-629. [CrossRef]

13. Shiau, J.K.; Ma, D.M. Development of an experimental solar-powered unmanned aerial vehicle. J. Chin. Inst. Eng. 2015, 38, 701-713. [CrossRef]

14. Lyu, Z.; Martins, J.R.R.A. Aerodynamic Design Optimization Studies of a Blended-Wing-Body Aircraft. J. Aircr. 2014, 51, 1604-1617. [CrossRef]

15. Charles, M.B.; Michael, J.V.T.; Ali, E. Multidisciplinary Aerodynamic Shape Optimization of a Composite Blended Wing Body Aircraft. In Proceedings of the 58th AIAA/ASCE/AHS/ASC Structures, Structural Dynamics, and Materials Conference, AIAA SciTech Forum, Grapevine, TX, USA, 9-13 January 2017. [CrossRef]

16. Andrew, T.W.; John, R.H.; Casie, M.C.; Ryan, P.; Cale, Z. Powered Low Speed Testing of the Hybrid Wing Body. In Proceedings of the 55th AIAA Aerospace Sciences Meeting, AIAA SciTech Forum, Grapevine, TX, USA, 9-13 January 2017. [CrossRef]

17. XFLR5 General Description. Available online: http://www.xflr5.com/xflr5.htm (accessed on 10 February 2019).

18. Hoak, D.E.; Finck, R.D. The USAF Stability and Control DATCOM; TR-83-3048; Air Force Wright Aeronautical Laboratories: Dayton, OH, USA, October 1960; (Revised 1978).

19. AXi Model Motors Products Catalogues. Available online: https://www.modelmotors.cz (accessed on 10 February 2019). 
20. Pixhawk Overview. Available online: http://ardupilot.org/copter/docs/common-pixhawk-overview.html (accessed on 10 February 2019).

21. Guidance for Ultra-Light Amateur-Built Flight Testing. Available online: https://www.caa.gov.tw/Article. aspx?a=2188\&lang=1 (accessed on 10 February 2019).

22. A Typical Airfield Traffic Pattern. Available online: https://en.wikipedia.org/wiki/Airfield_traffic_pattern (accessed on 10 February 2019). 